\title{
Nonhomogeneous Poisson Process Model of Summer High Temperature Extremes Over China
}

Meng Gao ( $\nabla$ gaomeng03@hotmail.com )

Yantai University https://orcid.org/0000-0003-2422-8328

Han Zhang

Yantai University

Aidi Zhang

Yantai University

Yueqi Wang

Yantai Institute of Coastal Zone Research

\section{Research Article}

Keywords: summer heat extremes, peak over threshold, nonhomogeneous Poisson process, teleconnection pattern

Posted Date: September 23rd, 2021

DOl: https://doi.org/10.21203/rs.3.rs-919065/v1

License: (c) (i) This work is licensed under a Creative Commons Attribution 4.0 International License. Read Full License

Version of Record: A version of this preprint was published at Stochastic Environmental Research and Risk Assessment on January 9th, 2022. See the published version at https://doi.org/10.1007/s00477021-02149-z. 


\title{
Nonhomogeneous Poisson process model of summer high temperature extremes over China
}

\author{
Meng Gao ${ }^{1 *}$, Han Zhang ${ }^{1}$, Aidi Zhang ${ }^{1}$,Yueqi Wang ${ }^{2,3}$ \\ ${ }^{1}$ School of Mathematics and Information Sciences, Yantai University, Yantai, 264005, China \\ ${ }^{2}$ Yantai Institute of Coastal Zone Research, Chinese Academy of Sciences, Yantai, 264003, China \\ ${ }^{3}$ Center for Ocean Mega-Science, Chinese Academy of Sciences, Qingdao 266071, China
}

E-mail: gaomeng03@hotmail.com, mgao@ytu.edu.cn 


\begin{abstract}
s
In this study, nonhomogeneous Poisson process (NHPP) models arising from the extreme value theory have been fitted to summer high temperature extremes (HTEs) at 359 meteorological stations over China. The seasonality and six prominent atmospheric teleconnection patterns in Northern Hemisphere are incorporated in the NHPP models reflecting the non-stationarity in occurrence rate in Poisson process of HTEs. In addition, Poisson regression model has also been applied to link HTEs and teleconnection patterns. The linkages of HTEs and teleconnection patterns have been identified in both NHPP modeling and Poisson regression. Composite maps of differences of 500-hPa geopotential height and wind fields in the positive and negative phases of teleconnection patterns are constructed to show the impacts of atmospheric circulation patterns on extreme heat events. The spatial pattern of the associated anticyclonic or cyclonic circulations with teleconnection patterns partly explains the spatial variability of the occurrences of summer HTEs over China.
\end{abstract}

Keywords: summer heat extremes, peak over threshold, nonhomogeneous Poisson process, teleconnection pattern 


\section{Declarations}

-Conflicts of interest

The authors declare no conflicts of interest.

-Funding Statement

This study was funded by the Key Program of Shandong Natural Science Foundation (No. ZR2020KF031) and the National Natural Science Foundation of China (No. 31570423).

Author's Contribution

Conceptualization, M.G.; Data curation, M.G.; Funding acquisition, M.G.; Investigation, M.G., and Y.W; Methodology, M.G., and Y.W.; Project administration, M.G.; Resources, M.G., Software, M.G., H.Z., A.Z.; Supervision, M.G. and Y.W.; Visualization, M.G., Y.W.; Writing - review \& editing, M.G., H.Z., A.Z., and Y.W.

-Availability of data and material

The data that support the findings of this study are openly available. The daily maximum temperatures are accessed from the National Meteorological Information Center (NMIC) of China Meteorological Administration (CMA). Registered users can download the datasets at https://data.cma.cn/. The Northern Hemisphere teleconnection pattern indices are provided by NOAA Center for Weather and Climate Prediction and available at https://www.cpc.ncep.noaa.gov/data/teledoc/telecontents.shtml. The NCEP/NCAR Reanalysis I dataset is obtained from the NOAA Earth System Research Laboratory at https://www.esrl.noaa.gov/psd/data/gridded/data.ncep.reanalysis.html.

-Code availability

The computer code for statistical modeling can be requested from the corresponding author via personal communication.

-Ethics approval

There is no biological experiment in this study.

-Consent to participate

All persons contributed to this work have been added into the author list, and the submission for publication has been approved by them.

-Consent for publication

All authors have seen and agreed to the submitted version of the manuscript. 


\section{Introduction}

Climate change, especially global warming, has been shown to exacerbate and trigger certain climate extremes, including extreme heat waves and intense precipitation events (Easterling et al. 2000). High temperature extremes (HTEs) are among the most frequently investigated climate extremes because of their disastrous impacts on human society and ecosystems (Stott et al. 2004; Brown et al. 2008; Robeson et al. 2014; Gao and Franzke 2017; Dosio et al. 2018; Luo et al. 2020).

The variations of HTEs and its associations with climate change and human activities have been extensively documented in previous literatures (Meehl et al. 2004; IPCC 2012; Luo and Lau 2017). Unlike the warming trend of global mean temperature, changes in temperature extremes at regional and local scales are diverse (Brown et al. 2008). Firstly, the long-term secular trend in HTEs was probably attributed to the combined effects of global warming and rapid urbanization (Freychet et al. 2017, Luo and Lau 2017). At a relatively shorter time scale, atmospheric circulation patterns are considered to be responsible for the changes in temperature extremes (Loikith et al. 2012; Gao et al. 2019a). The associations of atmospheric and oceanic teleconnection patterns with HTEs have received wide attentions in recent decades (Kenyon and Hegerl 2008; Keellings and Waylen, 2015; Carney et al. 2020; Luo et al. 2020; Tu and Yan 2021).

For a long time, extreme value theory (EVT) has been applied in the studies of warm and cold temperature extremes (Kharin and Zwiers 2005; Kharin et al. 2007; Brown et al. 2008; Gao and Zheng 2018; Carney et al. 2020). According to EVT, extreme events could be characterized by the probability distributions such as the generalized extreme value (GEV) distribution and generalized Pareto (GP) distribution (Coles 2001). The two probability distributions are respectively applied for block maxima and series of peaks over threshold (POT). In earlier studies, the statistical modelling of climate extremes using GEV or GPD has been based on stationarity assumption (Li et al. 2013; Gao et al. 2016; Hossain et al. 2021). However, more and more recent studies showed that the non-stationarity due to seasonal variations and/or long-term trends should be taken into account in modelling climate extremes (Brown et al. 2008; Keellings and Waylen 2015; Gao and Zheng 2018; Tu and Yan 2021). In the nonstationary modelling of climate extremes, their associations with time or climate drivers could be modeled by introducing time-varying parameters in probability density functions (pdfs) of extreme values (Katz 2010; Siliverstovs et al. 2010; Gao and Zheng 2018; Aksu 2021). Actually, there is an 
approximate relationship between the GEV and GPD functions, where the GPD function is approximately the tail distribution function for the GEV (Pickands 1975). Ding et al. (2008) showed that the POT-GPD approach was preferable due to its simplicity and independence on the sample size of the primitive series.

Moreover, a well-known result of EVT states that, in an independent and identically distributed (i.i.d.) series, the occurrences of excess over a sufficiently extreme threshold $\mu$ follow a Poisson Process (PP), where the excesses follow a GPD distribution (Coles 2001). A PP model is a random point process assuming that points occur randomly at a given intensity $\lambda(>0)$, and statistical modeling based on a PP requires the estimation of the intensity parameter. Then, the occurrence of extreme environmental events such as fires, earthquakes or heat waves could be modeled as a PP (Ogata 1988; Abaurrea and Cebrián 2002). Also, non-stationarity could also be incorporated in the framework of PP model by allowing a time-varying intensity parameter $\lambda(t)$ as a function of covariates such as time trends, seasonal terms and/or climate indices. Accordingly, the PP model becomes a nonhomogeneous Poisson process (NHPP), and climate extremes are linked to climate indices.

The associations of HTEs over China with climate teleconnections have been extensively studied. It has been suggested that the occurrence of HTEs in southern and eastern China are attributed to the western North Pacific subtropical high (Ding et al. 2010; Luo and Lau 2017; Gao and Zheng 2018). The interannual variations of HTEs over China have also been related to the East Asian jet stream (EAJS) and El Niño-Southern Oscillation (ENSO) (Wang et al. 2013; Gao and Franzke 2017; Luo and Lau 2017; Gao et al. 2020). Barnston and Livezey (1987) have identified ten atmospheric teleconnection patterns those reflect large-scale changes in the atmospheric wave and jet stream patterns in the Northern Hemisphere. The Northern Hemisphere teleconnection patterns, which directly influence the weather systems over vast areas, are the reflection of internal atmospheric dynamics.

The primary objective of this study is to reveal the statistical associations of summer high temperature extremes over China with six atmospheric teleconnection patterns by using the NHPP approach. The links revealed by the NHPP model will also be compared with that revealed by Poisson regression model for monthly HTEs on atmospheric teleconnections. In addition, atmospheric circulation composite analysis is conducted to illustrate the role of these teleconnection patterns in influencing summer heat waves in China. The following sections are organized as follows. Data and methods are described in Sect. 2 and 3, respectively. The results are presented in Sect. 4 and discussed 
in Sect. 5. Finally, a brief conclusion will be given in Sect. 6.

\section{Data}

The datasets of daily maximum temperatures $\left(\mathrm{T}_{\max }\right)$ are accessed from the National Meteorological Information Center (NMIC) of China Meteorological Administration (CMA). In this study, air temperature data from 359 meteorological stations having the good quality and continuous daily records from 1956 to 2013 are used. These 359 meteorological stations are mainly located in central and eastern China, and the latitudes approximately range from $18^{\circ} \mathrm{N}$ to $52^{\circ} \mathrm{N}$ (Figure 1 ). The extended summer seasons lasting May-September (MJJAS) is adopted instead the conventional JuneAugust (JJA) summer season in the Northern Hemisphere in order to avoid missing HTEs in lower latitudes.

The monthly teleconnection pattern indices used in this study are calculated by the Climate Prediction Center (CPC) based on the Rotated Principal Component Analysis (RPCA) used by Barnston and Livezey (1987). These teleconnection indices are provided by NOAA Center for Weather and Climate Prediction and available at https://www.cpc.ncep.noaa.gov/data/teledoc/telecontents.shtml. The ten indices are mutually uncorrelated by construction, which makes them particularly suitable for use as explanatory variables in statistical modeling (Mailer et al. 2006). In this study, four indices have been excluded by an exploratory statistical analysis, and only six of them are used in this study for further statistical modeling.

The NCEP/NCAR reanalysis data (1948-present) of monthly mean geopotential height and wind fields at 500-hPa level are also used to show the differences of large-scale atmospheric circulation patterns in the positive and negative phases of teleconnection patterns. The spatial resolution of global dataset is $2.5^{\circ} \times 2.5^{\circ}$ (Kalnay et al. 1996). These data are downloaded from the website of National Centers for Environmental Prediction/National Center for Atmospheric Research.

\section{Methodology}

3.1 Poisson process and POT-GPD approach

To define a HTE, we use the POT-GPD approach. The probability distribution function $\mathrm{F}(\mathrm{x})$ of GPD for is given as follows (Pickands 1975) 


$$
F(x)=1-\left\{1+k \frac{x-\mu}{\sigma}\right\}^{-1 / k}
$$

where $x>\mu, \sigma>0$, and $1+k \frac{x-\mu}{\sigma}>0$. Here, $x$ is $T_{\max }$. The three parameters $\mu, \sigma$, and $k$ are location, scale and shape parameters, respectively. The selection of $\mu$ is crucial for the success of the GPD modelling, which is also the threshold to identify the HTEs from $T_{\max }$ time series. In this study, we have tested the $95^{\text {th }}, 97^{\text {th }}$, and $99^{\text {th }}$ percentiles of $T_{\max }$ as the threshold, and the diagnostic results show that the $97^{\text {th }}$ percentile is preferable at most stations. Excesses in consecutive days are considered as a single extreme heat event.

The occurrences of HTEs are modelled by a nonhomogeneous Poisson process (NHPP; Cox and Isham 1980). Unlike the Poisson process with a constant intensity parameter representing complete randomness, a NHPP with a time-varying rate is very flexible to capture deviation from complete randomness, in terms of either clustering or regularity (Gao et al. 2021). In this study, the rate parameter $\lambda(t)$ is expressed a function of covariates, and specifically the seasonal terms and atmospheric teleconnection indices. In order to guarantee the positivity of $\lambda(t)$, a logarithm link is usually used,

$$
\log (\lambda(t ; \beta))=\boldsymbol{X}^{T}(t) \beta
$$

where $\boldsymbol{X}^{T}(t)$ is the row vector of the covariates at time $t$ and $\beta$ the vector of coefficients. The covariates include 6 teleconnection indices (West Pacific pattern, WP; Polar/Eurasia pattern, PEA; East Atlantic Pattern, EA; East Atlantic/Western Russia pattern, EAWR; Scandinavia pattern, SCA; Pacific/North American pattern, PNA) and two first order harmonics (sine and cosine) representing seasonality. The estimated coefficients reflect the associations of HTEs with teleconnection patterns, and their statistical significances are determined by a likelihood ratio test.

All statistical analyses including the exploratory analyses, fitting and validating of the NHPP model, are completed with the statistical computing environment R (R Core Team 2019). Specifically, two packages extRemes (Gilleland and Katz 2011) and NHPoisson (Cebrián et al. 2015) are applied to implement the POT modeling and NHPP modeling, respectively. More details about POT modeling and NHPP modeling is referred to Gilleland and Katz (2011) and Cebrián et al. (2015).

\subsection{Poisson regression model}

For any meteorological station, the number of HTEs in any calendar month (denoted as $N$ ), could 
also be counted and modeled with a discrete Poisson distribution:

$$
P(N=n)=\frac{\lambda^{n} e^{-\lambda}}{n !}, n=0,1,2, \cdots
$$

Analogously, a constant rate parameter $\lambda$ corresponds to the simplest homogeneous Poisson process, while a time-varying rate $\lambda_{t}$ corresponds to a NHPP. The subscript $t$ is the month index. Then, the monthly HTE counts N could be modeled using the Poisson regression with the log-link function:

$$
\begin{gathered}
N \mid \lambda \sim \operatorname{Poisson}(\lambda) \\
\log (\lambda)=\alpha_{0}+\sum_{s=1}^{4} \gamma_{s} x_{s}+\sum_{k=1}^{6} \alpha_{k} z_{k}
\end{gathered}
$$

Eq.(4) means that the monthly HTE count N, conditional on a linear predictor $\lambda$, is Poisson distributed. Like Gao et al. (2021), the seasonality is also considered in Poisson regression by including four binary indictor variables $\mathrm{x}_{\mathrm{S}}$ from May to July, while the fifth indictor for August is redundant and ignored. $\mathrm{z}_{\mathrm{k}}$ is the monthly index of the six teleconnection patterns, and $\alpha_{\mathrm{k}}$ also reflect the associations of HTEs with atmospheric teleconnection patterns. The Poisson regression has also been completed with the statistical computing environment R (R Core Team 2019).

\section{Results}

Firstly, two meteorological stations (Hailun and Guiyang), which are located at the northeast and southwest China (figure 1), are selected to verify the feasibility of GPD modeling and NHPP modeling. Figure 2 shows the empirical distribution (histogram) and modeled probability density (blue dashed line) of $T_{\max }-\mu$, where $\mu$ is the $97^{\text {th }}$ percentile of all summer $T_{\max }$ values in $1956-2013$. The consistency between the empirical and modeled distributions indicates the reasonability of threshold selection and POT modeling of HTEs. Also, the qq-plots for the empirical quantiles against model quantiles are shown in figure 2 . The straight one-to-one line of points within the $95 \%$ confidence bands also indicates a good fitting model, although the non-stationarity has not been considered in the POT modeling. The NHPP modeling of these two stations is validated by inspecting the residual qq-plot (figure 3), which does not show any evidence against the fitted NHPP models.

Figure 4 shows the spatial distribution of the estimated coefficients $\widehat{\beta}$ in NHPP models using the maximum likelihood estimation method at 359 meteorological stations over China. Statistical significance is determined with a likelihood ratio test at the $5 \%$ significance level. The linkage between 
WP and HTEs is clearly revealed by the NHPP modeling, and the statistically significant coefficients are mainly distributed in northeast China (figure 4a). It means the positive WP phase is associated with more extreme heat events in northeast China. The linkage between PEA and HTEs is similar to that between WP and HTEs. The positive and statistically significant coefficients are also distributed in northeast China (figure 4b). Negative coefficients, either statistically significant or nonsignificant, are prone to distributed in the southern part of China. The impact of EA on HTEs is consistent over China (figure 4c). Most coefficients for EA are positive, and statistically significant coefficients have been identified at 180 stations. Stations with statistically significant negative EAWR coefficients are mainly distributed in southern China indicting a decrease in HTEs in the negative phase of EAWR (figure 4d). Negative correlations between SCA and HTEs are mainly distributed over southeastern China, while positive correlations are in other regions of China (figure 4e). Statistically significant association between PNA and HTEs has only been detected at a few meteorological stations (figure4 f), where positive coefficients are in northeastern China and negative ones are in southwestern China.

Figure 5 shows the estimated coefficient $\alpha_{\mathrm{k}}$ in the Poisson regression models for monthly HTEs counts. These coefficients are also estimated using the maximum likelihood method, and the statistical significance is determined with a t-test at the $5 \%$ significance level. The spatial patterns of $\widehat{\alpha}$ and $\widehat{\beta}$ in figure 4 and figure 5 are almost similar indicting the reliability of the associations of HTEs with atmospheric teleconnection patterns revealed by the two Poisson process models. These consistency between $\widehat{\alpha}$ and $\widehat{\beta}$ is further presented in figure 6. In summary, we note that the results of NHPP modeling and Poisson regression for HTEs are consistent at most stations.

To investigate the impact of atmospheric teleconnection patterns on extreme heat events over China, atmospheric circulation composite analysis has also been conducted in this study. Figure 7 shows the composite circulation maps presenting the differences of geopotential height and wind fields at 500-hPa level in the positive and negative phases of these six atmospheric teleconnection patterns. Red/blue shaded contours indicate positive/negative value of the 500-hPa geopotential height (Z500) differences, and green vectors represent the difference of wind vector above the 0.75 quantile of all wind speeds. In general, anticyclones and positive geopotential height differences correspond to the positive coefficients in figure 4 and figure 5, while cyclones and negative geopotential height differences correspond to the negative coefficients. The spatial patterns of composite circulation maps are almost consistent with that of estimated coefficients in NHPP modeling and Poisson regression. 
This result indicates the feasibility of explaining the occurrence of extreme heat events from the view of large scale atmospheric circulation patterns.

\section{Discussions}

Large-scale atmospheric teleconnection, which is a reflection of internal atmospheric dynamics, strongly influences regional weather system such temperature and precipitation anomalies and the variability of storm tracks, and jet stream location/ intensity (Franzke et al. 2020). Barnston and Livezey (1987) have identified ten atmospheric teleconnection patterns in the Northern Hemisphere. Lim and Kim (2013) showed that East Asia winter temperature variation could be partly explained by these Northern Hemisphere teleconnection patterns. Previous studies focused more attention on the impacts of teleconnection patterns on climate variability in winter season (Liu et al. 2014; Oh et al. 2017; Shi et al. 2019; Yang et al. 2019). Yu et al. (2019) showed that the associations of warm extremes with atmospheric teleconnection patterns were weaker than that of cold extremes over North America. In this study, we have investigated the impacts of teleconnection patterns on summer heat extremes by using Poisson process models that link HTEs to teleconnection patterns.

The WP teleconnection pattern, which is characterized by a dipole in the geopotential height field in the western sector of North Pacific with negatively correlated centers in the mid-latitude and subtropics, exists throughout the year (Barnston and Livezey 1987). In the positive phase of WP pattern, an anomalous cyclone and an anomalous anticyclone develop in the low and middle latitudes of the East Asia area, respectively. The western edge of anticyclonic circulations might extend from North Pacific to the northeastern China promoting the probability of occurrence of extreme heat events there (figure 4a).

The PEA pattern is closely associated with the connection between the Arctic polar vortex activity and the midlati-tude circulation over the Asian continent (Barnston and Livezey 1987, Gao et al. 2019b). The impact of the PEA pattern on regional weather systems is through by affecting the distributions of blocking and transient eddy kinetic energy (EKE) over North Atlantic/Eurasia (Gao et al; 2019b). The positive phase of this pattern consists of negative geopotential height anomalies over the polar region and positive height anomalies over northern China and Mongolia, where the positive correlations between HTEs and PEA teleconnection index are detected over northeaster China in this 
study (figure 4b).

In boreal summer, the EA pattern is the second dominant mode of low-frequency variability in the Euro-Atlantic region. It consists of a north-south dipole of anomaly centers spanning the North Atlantic from east to west (Barnston and Livezey 1987), and the corresponding circulation anomalies significantly influence temperature and precipitation over Europe (Wulff et al. 2017). The EA pattern appears as a leading mode in all seasons, and is structurally similar to the North Atlantic Oscillation (NAO). The positive phase of the EA pattern is associated with above-average surface temperatures in Europe in all months. In this study, we also find that HTEs over China are also related to the positive phase of the EA pattern (figure 4c).

The EAWR pattern is one of three prominent teleconnection patterns that affect Eurasia in all months (Barnston and Livezey 1987). The positive phase is associated with positive geopotential height anomalies located over Europe and northern China leading to above-average temperatures (Lim 2015). Previous studies investigated the climatic impacts of EAWR pattern in winter season or in Europe (Liu et al. 2014; Oh et al. 2017). The remote impact of EAWR even reaches the Southern Hemisphere such as the Amazon rain forests (Gonsamo et al. 2015). In this study, the significant impact of EAWR pattern on summer extreme heat events over China has also been identified.

The SCA pattern, which was referred to as Eurasian Type 1 pattern in Barnston and Livezey (1987), has a primary circulation center over the Scandinavian Peninsula. It also consists of two weaker centers of opposite sign over West Europe and eastern Russia/western Mongolia. Accordingly, its positive phase is characterized by prominent anticyclonic circulations around the Scandinavian Peninsula, giving rise in winter to below-average temperatures across central Russia and West Europe (Bueh and Nakamura 2007). Shi et al. (2019) has identified the influence of four teleconnection patterns (WP, EA, EAWR, and SCA) on the wintertime surface air temperature over southern China. The associations of summer HTEs with these teleconnection patterns are also detected in this study in the Poisson process model. For SCA, the positive impact on summer extreme heat events range from the northeastern China to southwestern China, while the negative impact is over the southeastern China.

The PNA teleconnection pattern is one of the leading patterns of Northern Hemisphere mid-latitude variability (Barnston and Livezey 1987, Franzke et al. 2011). Its climatic impacts are reflected in the displacement of jet streams and storm tracks over Western and Northern Pacific (Mailier et al. 2006; Gao et al. 2021). In this study, the impact of PNA teleconnection pattern on 
summer HTEs is not significant as that of other teleconnection patterns. Positive and statistically significant coefficients are less and distributed over southwestern China.

\section{Conclusions}

In this study, we have fitted a NHPP model to the summer HTEs over China in order to find the linkages between summer HTEs and large scale atmospheric teleconnection patterns in the Northern Hemisphere. Non-stationarity and seasonality have been effectively modeled in the NHPP modeling and Poisson regression. The associations of summer HTEs with six atmospheric teleconnection pattern indices are clearly identified by the NHPP modeling and Poisson regression. Composite analysis also shows that anticyclonic circulations are basically consistent with the occurrences of HTEs verifying the impacts of large scale atmospheric circulation patterns on extreme heat events over China. The spatial pattern of geopotential height anomalies related to large scale atmospheric circulation partly explained the spatial variability of summer HTEs over China. In addition, the NHPP model could also be used to infer the number of HTE occurrence in a summer and occurrence time of the first extreme heat event at any meteorological station. In future, the NHPP modeling could be extended to bivariate extreme model or other nonhomogeneous Poisson process models for climate extremes.

\section{Acknowledgements}

This study was funded by the Key Program of Shandong Natural Science Foundation (No. ZR2020KF031) and the National Natural Science Foundation of China (No. 31570423). 


\section{References}

Abaurrea J and Cebrián AC (2002) Drought analysis based on a cluster Poisson model: distribution of the most severe drought. Clim Res 22(4): 227-235

Aksu H (2021) Nonstationary analysis of the extreme temperatures in Turkey. Dynam Atmos Oceans 95: 101238

Barnston A G and Livezey R E (1987) Classification, seasonality, and persistence of low-frequency atmospheric circulation patterns. Mon Weather Rev 115: 1083-1126

Brown S J, Caesar J and Ferro C A T (2008) Global changes in extreme daily temperature since 1950. J Geophys Res 113: D05115

Bueh C and Nakamura H 2007 Scandinavian pattern and its climatic impact Q. J. R. Meteorol. Soc.133 2117-2131.

Carney M, Azencott R and Nicol M (2020) Nonstationarity of summer temperature extremes in Texas. Int J Climatol 40: 620-640

Cebrián A C, Abaurrea J and Asín J (2015) NHPoisson: An R Package for fitting and validating Nonhomogeneous Poisson Processes. J Stat Softw 64(6): 1-24

Cox D R and Isham V (1980) Point processes. London, U.K. Chapman \& Hall

Ding T, Qian W and Yan Z (2010) Changes in hot days and heat waves in China during 1961-2007. Int J Climatol 30: 1452-1462

Ding Y, Cheng B and Jiang Z (2008) A newly-discovered GPD-GEV relationship together with comparing their models of extreme precipitation in summer. Adv Atmos Sci 25(3): 507-516

Dosio A, Mentaschi L, Fischer E M and Wyser K (2018) Extreme heat waves under $1.5 \circ \mathrm{C}$ and $2{ }^{\circ} \mathrm{C}$ global warming. Environ Res Lett 13: 054006

Easterling D R, Meehl G A, Parmesan C and Mearns L O (2000) Climate extremes: observations, modeling, and impacts. Science 289: 2068-2074

Franzke C L E, Barbosa S, Blender R, Fredriksen H B, Laepple T, Lambert F, Nilsen T, Rypdal K, Rypdal M, Scotto MG, Vannitsem S, Watkins NW, Yang L and Yuan N (2020) The structure of climate variability across scales. Rev Geophys 58: e2019RG000657

Franzke C L E, Feldstein S B and Lee S (2011) Synoptic analysis of the Pacific-North American teleconnection pattern. Q J R Meteorol Soc 137: 329-346

Freychet N, Tett S, Wang J and Hegerl G (2017) Summer heat waves over eastern China: dynamical 
processes and trend attribution. Environ Res Lett 12: 024015

Gao M, Mo D and Wu X (2016) Nonstationary modeling of extreme precipitation in China. Atmos Res 182: 1-9

Gao M and Franzke C L E (2017) Quantile regression-based spatiotemporal analysis of extreme temperature change in China. J Clim 30: 9897-9913

Gao M and Zheng H (2018) Nonstationary extreme value analysis of temperature extremes in China. Stoch Environ Res Risk Assess 32: 1299-1315

Gao M, Yang Y, Shi H and Gao Z (2019a) SOM-based synoptic analysis of atmospheric circulation patterns and temperature anomalies in China. Atmos Res 220: 46-56

Gao M, Sun Y-D and Zheng Q (2021) Associations of atmospheric teleconnections with wintertime extratropical cyclones over East Asia and Northwest Pacific. Clim Dyn 57(7), 2079-2092

Gao N, Bueh C, Xie Z and Gong Y (2019b) A novel identification of the Polar/Eurasia Pattern and its weather impact in May. J Meteorol Res 33(5): 810-825

Gao T, Luo M, Lau N C and Chan T O (2020) Spatially distinct effects of two El Niño types on summer heat extremes in China. Geophys Res Lett 47: e2020GL086982

Gilleland E and Katz R W (2011) New software to analyze how extremes change over time. Eos 92(2): $13-14$

Gonsamo A, Chen J M and D’Odorico P (2015) Underestimated role of East Atlantic-West Russia pattern on Amazon vegetation productivity. P Natl Acad Sci USA 112 (10): E1054-E1055

Hossain I, Imteaz MA and Khastagir A (2021) Effects of estimation techniques on generalised extreme value distribution (GEVD) parameters and their spatio-temporal variations. Stoch Environ Res Risk Assess. https://doi.org/10.1007/s00477-021-02024-X

Kalnay E, Kanamitsu M, Kistler R et al. (1996) The NCEP/NCAR 40-year reanalysis project. Bull Am Meteorol Soc 77(3): 437-471

Katz R (2010) Statistics of extremes in climate change. Clim Change 100: 71-76

Keellings D and Waylen P (2015) Investigating teleconnection drivers of bivariate heat waves in Florida using extreme value analysis. Clim Dyn 44: 3383-3391

Kenyon J and Hegerl G C (2008) Influence of modes of climate variability on global temperature extremes. J Clim 21: 3872-89

Kharin V V and Zwiers F W (2005) Estimating extremes in transient climate change simulations. J 
Clim 18: 1156-1173

Kharin V V, Zwiers F W, Zhang X and Hegerl G C (2007) Changes in temperature and precipitation extremes in the IPCC ensemble of global coupled model simulations. J Clim 20: 1419-1444

Li Z, Brissette F and Chen J (2013) Finding the most appropriate precipitation probability distribution for stochastic weather generation and hydrological modelling in Nordic watersheds. Hydrol Process 27(25): 3718-3729

Lim Y K (2015) The East Atlantic/West Russia (EA/WR) teleconnection in the North Atlantic: climate impact and relation to Rossby wave propagation. Clim Dyn 44: 3211-3222

Lim Y K and Kim H D (2013) Impact of the dominant large-scale teleconnections on winter temperature variability over East Asia. J Geophys Res- Atmosphere 118: 7838-7848.

Liu Y, Wang L, Zhou W and Chen W (2014) Three Eurasian teleconnection patterns: Spatial structures, temporal variability, and associated winter climate anomalies. Clim Dyn 42(11-12): 2817-2839

Loikith P C, Lintner B R and Sweeney A (2017) Characterizing large-scale meteorological patterns and associated temperature and precipitation extremes over the northwestern United States using self-organizing maps. J Clim 30: 2829-2847.

Luo M and Lau N-C (2017) Heat waves in southern China: synoptic behavior, long-term change, and urbanization effects. J Clim 30: 703-720

Luo M and Lau N-C (2018) Amplifying effect of ENSO on heat waves in China. Clim Dyn 52: 32773289,

Luo M, Lau N-C, Zhang W, Zhang Q and Liu Z (2020) Summer high temperature extremes over China linked to the Pacific Meridional Mode. J Clim 33(14): 5905-5917

Mailier P J, Stephenson D B, Ferro C A T and Hodges K I (2006) Serial clustering of extratropical cyclones. Mon Weather Rev 134(8): 2224-2240

Meehl G A, Tebaldi C, Walton G, Easterling D and McDaniel L (2009) Relative increase of record high maximum temperatures compared to record low minimum temperatures in the U.S. Geophys Res Lett 36: L23701

Ogata Y (1988) Statistical models for earthquake occurrences and residual analysis for point processes. J Am Stat Assoc 83(401) : 9-27

Oh H, Jhun J-G, Ha K-J and Seo K-W (2017) Combined effect of the East Atlantic/West Russia and Western Pacific teleconnections on the East Asian winter monsoon. Asia-Pac J Atmos Sci 53: 
Pickands J (1975) Statistical inference using extreme order statistics. Ann Stat 3(1): 119-131

R Core Team (2019) R: A Language and Environment for Statistical Computing. R for Statistical Computing, Vienna. https://www.R-Project.org

Robeson S M, Willmott C J and Jones P D (2014) Trends in hemispheric warm and cold anomalies. Geophys Res Lett 41(24): 9065-9071

Shi N, Zhang D, Wang Y and Tajie S (2019) Subseasonal influences of teleconnection patterns on the boreal wintertime surface air temperature over southern China as revealed from three reanalysis datasets. Atmosphere 10(9): 514

Siliverstovs B, Ötsch R, Kemfert C, Haeger CC, Haas A and Kremers H (2010) Climate change and modelling of extreme temperatures in Switzerland. Stoch Environ Res Risk Assess 24: 311-326

Stott P A, Stone DA and Allen M R (2004) Human contribution to the European heatwave of 2003. Nature 432: 610-613.

Tu K and Yan Z W (2021) Non-stationary climate changes in summer high-temperature extremes in Shanghai since the late 19th century. Int J Climatol 41: E718-E733

Wang W, Zhou W, Wang X, Fong S K and Leong K C (2013) Summer high temperature extremes in southeast China associated with the East Asian jet stream and circumglobal teleconnection. J Geophys Res-Atmos. 118: 8306-8319

Wulff C O, Greatbatch R J, Domeisen D I V, Gollan G and Hansen F (2017) Tropical forcing of the summer East Atlantic pattern. Geophys Res Lett 44(21): 11166-11173

Yang Y, Xie N and Gao M (2019) The relationship between the wintertime cold extremes over East Asia with large-scale atmospheric and oceanic teleconnections. Atmosphere :10 813

Yu B, Lin H and Soulard N (2019) A comparison of north American surface temperature and temperature extreme anomalies in association with various atmospheric teleconnection patterns. Atmosphere 10(4): 172 


\section{Figures and Captions}

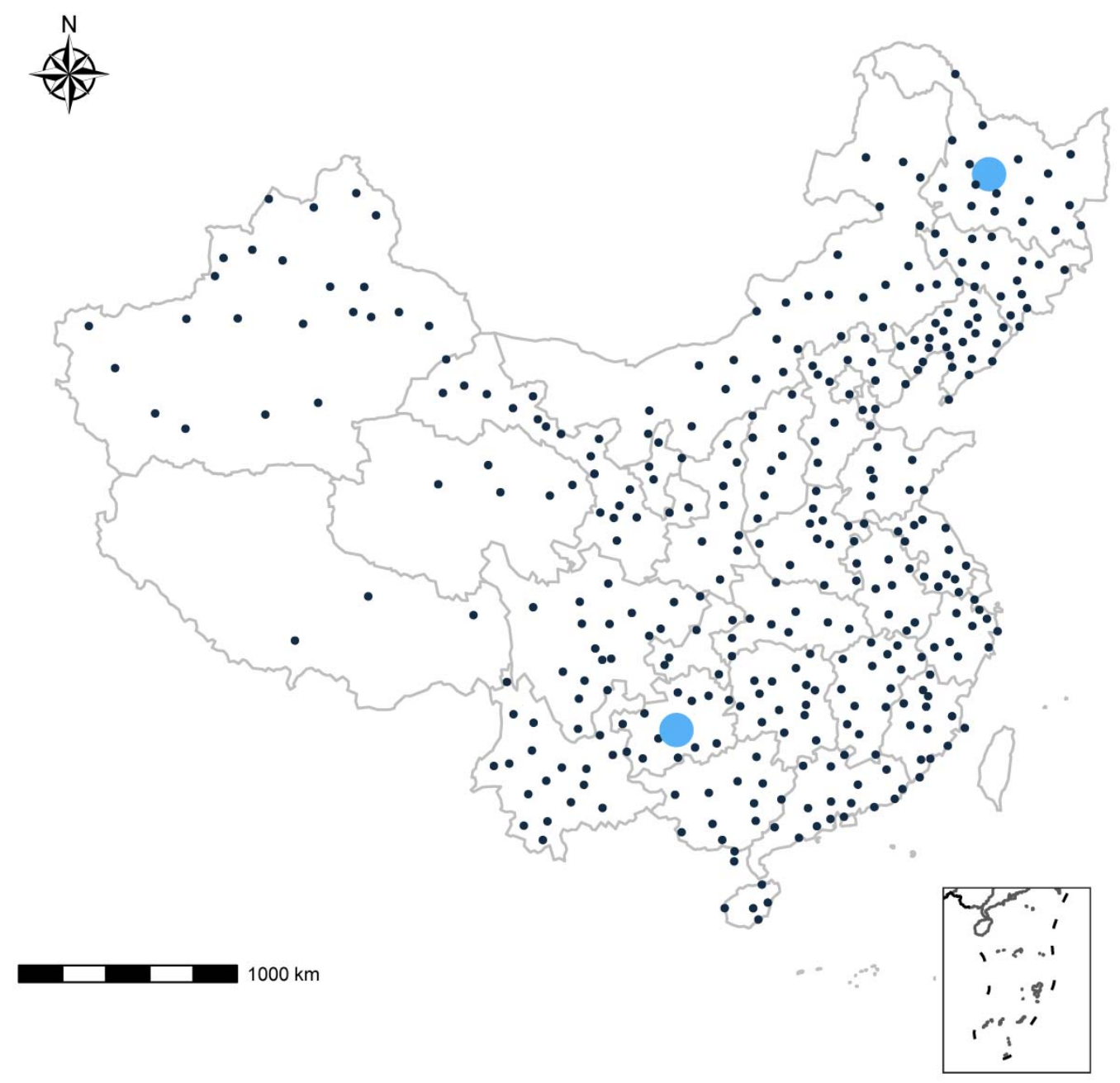

Figure 1. Geographical distribution of the 359 meteorological stations in China. The two bigger blue dots indicate locations of the two stations (Hailun and Guiyang). 

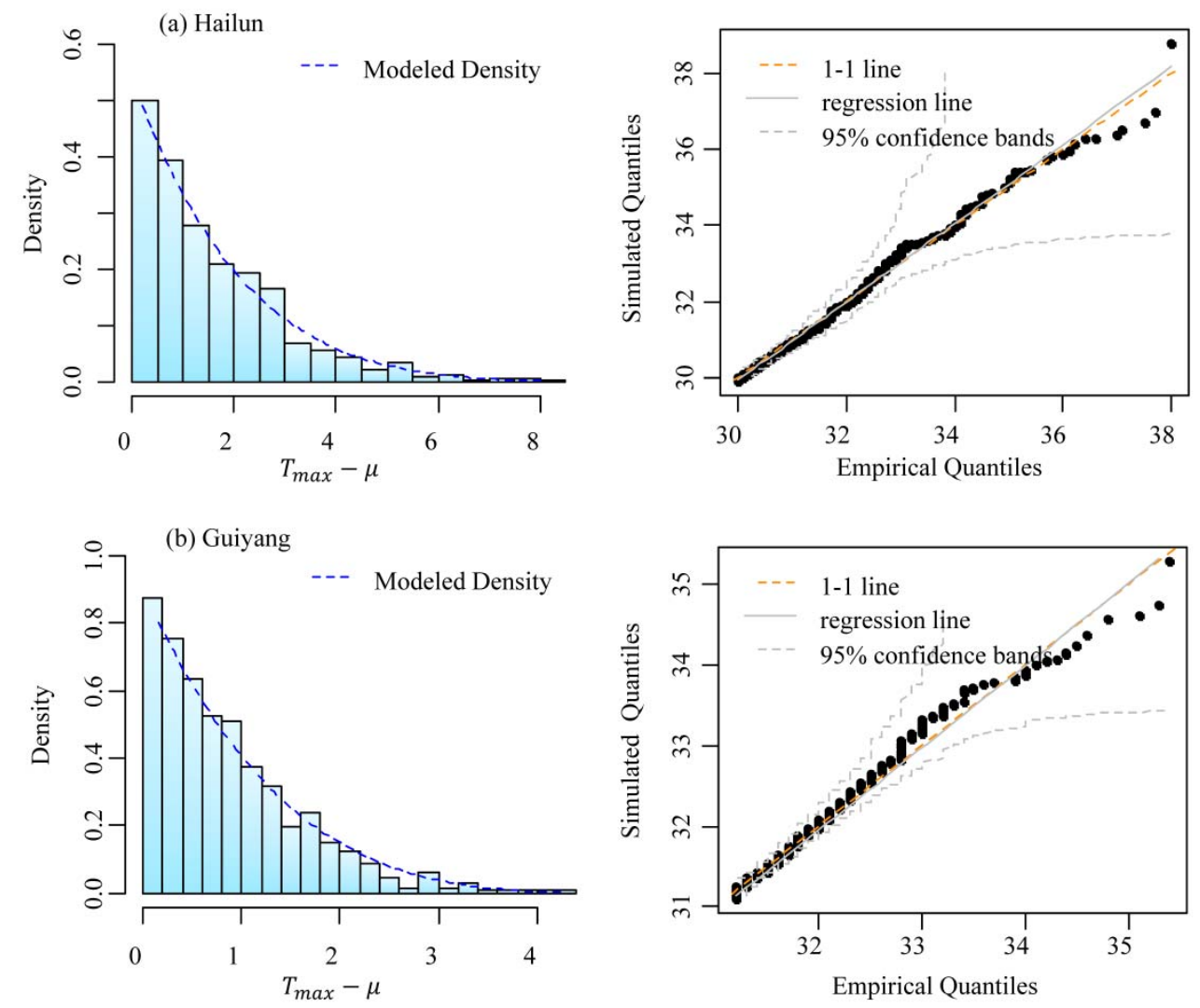

Figure 2. The results of GPD modeling for summer $T_{\max }$ at two stations Hailun (top row) and Guiyang (bottom row). The left column shows the empirical density (histograms) and modeled probability (dashed lines), while the right column shows the empirical quantiles vs simulated quantiles. The estimated parameters of GPD model, Hailun: $\hat{\mu}=29.9^{\circ} \mathrm{C}, \hat{\sigma}=1.8467$, $\hat{k}=-0.1373$; Guiyang: $\hat{\mu}=31.1^{\circ} \mathrm{C}, \hat{\sigma}=1.1024, \hat{k}=-0.2003$. 

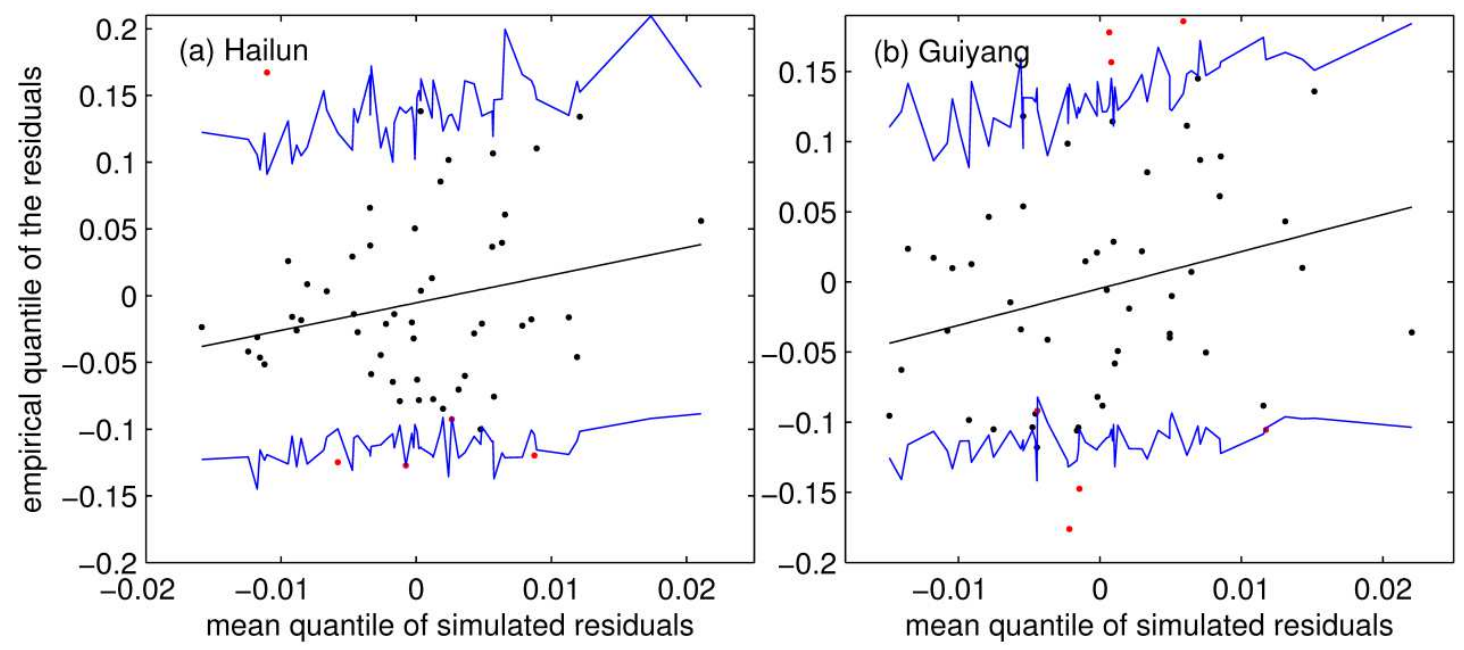

Figure 3. The residual qqplots for validating the NHPP modeling. The blue solid lines indicate the $95 \%$ confidence bands, while the black line is the regression line. 

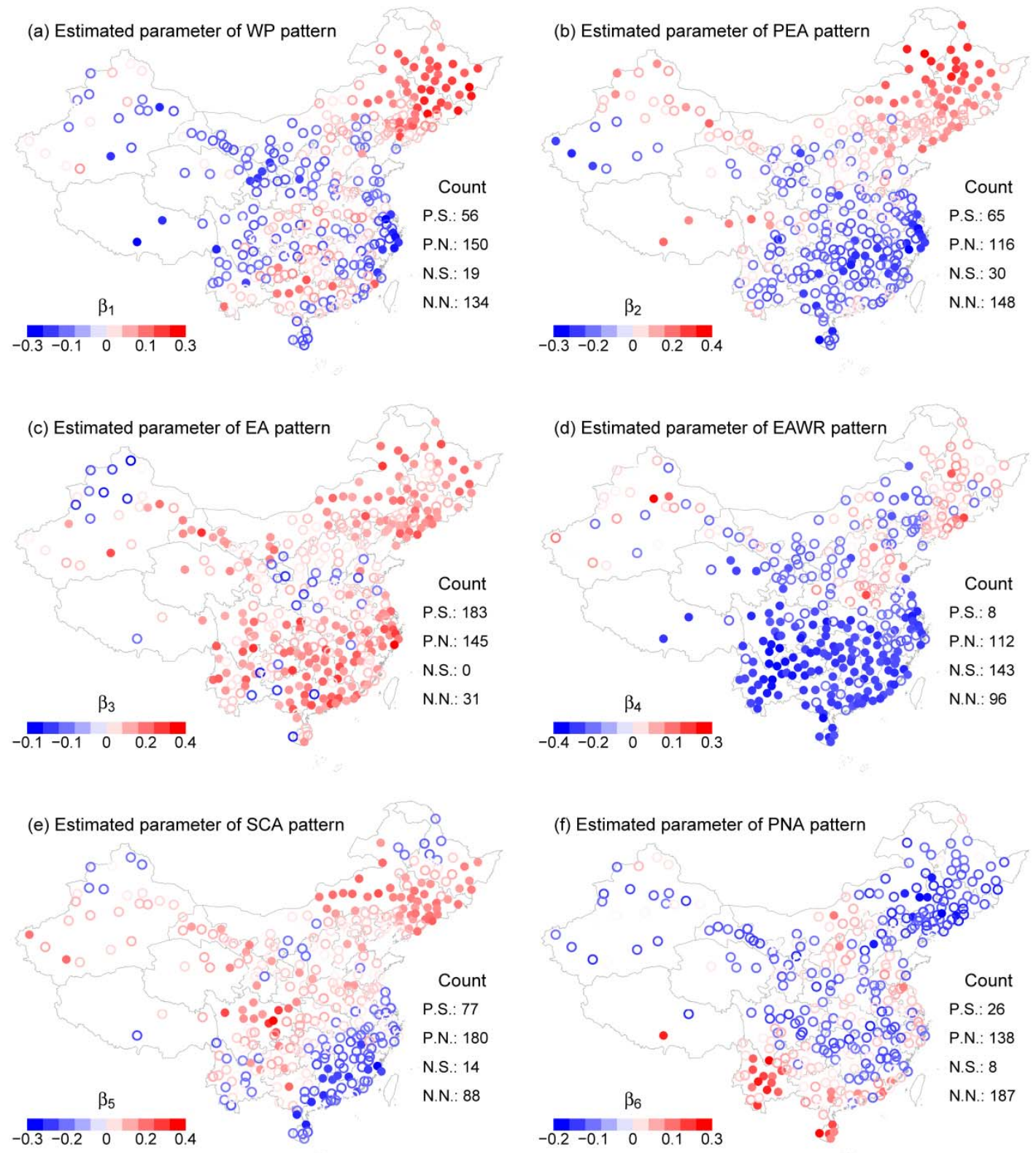

Figure 4. Spatial patterns of estimated coefficients $\beta$ in NHPP model at 359 meteorological stations over China. The filled symbols represent statistically significant coefficients at the $5 \%$ level (P.S. positive and significant, P.N. positive and nonsignificant, N.S. negative and significant, N.N. negative and non-significant). 

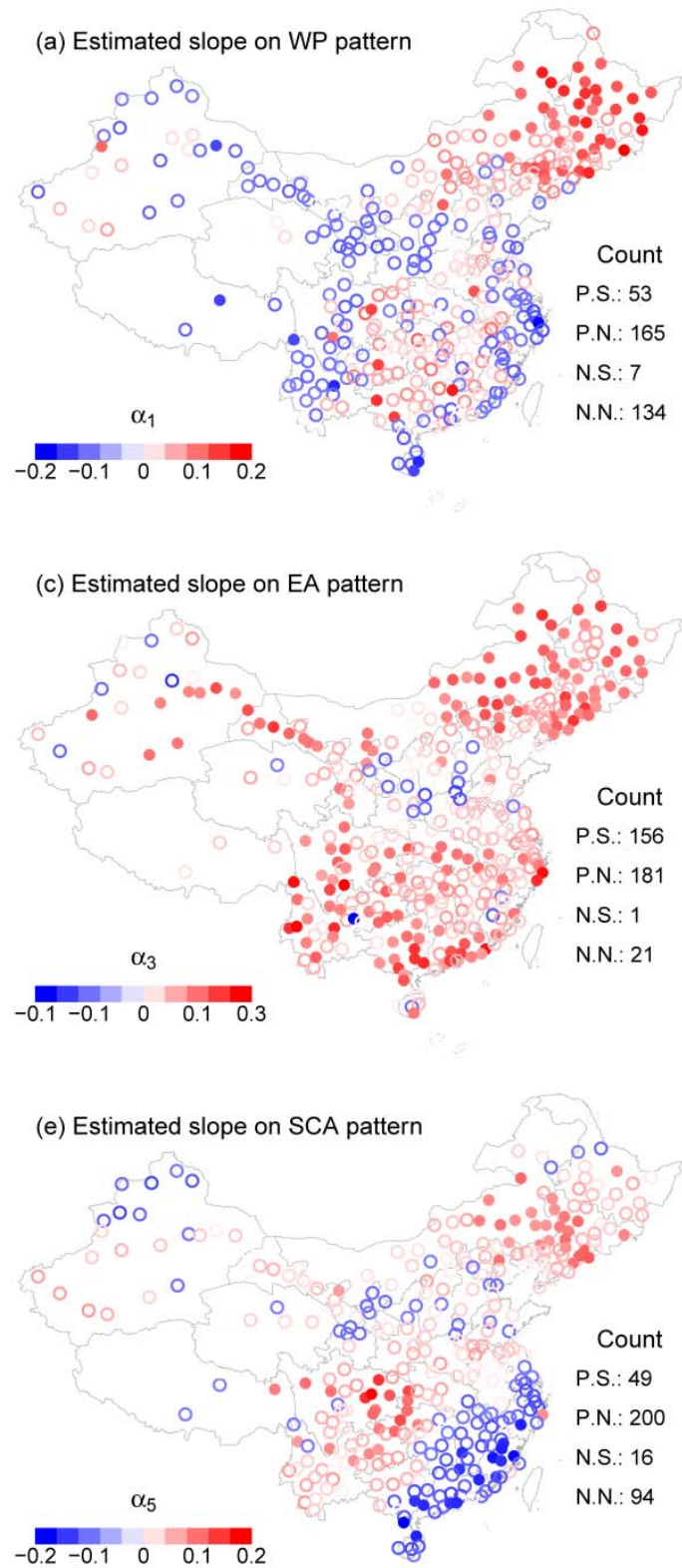

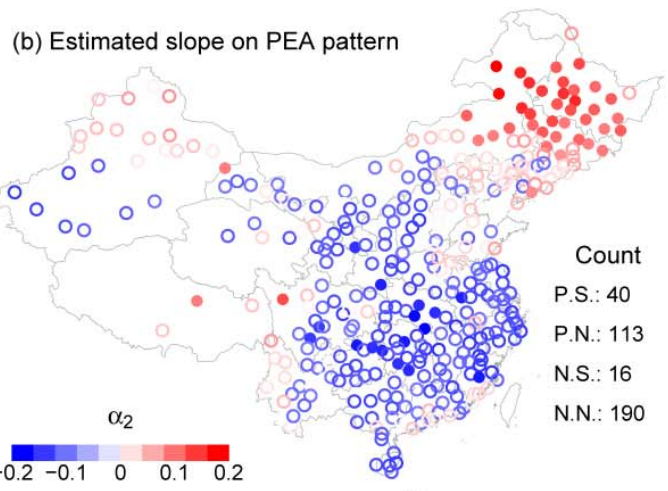

(d) Estimated slope on EAWR pattern

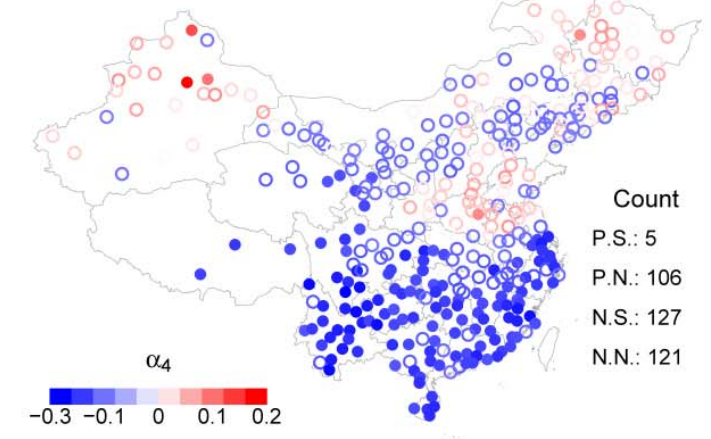

(f) Estimated slope on PNA pattern

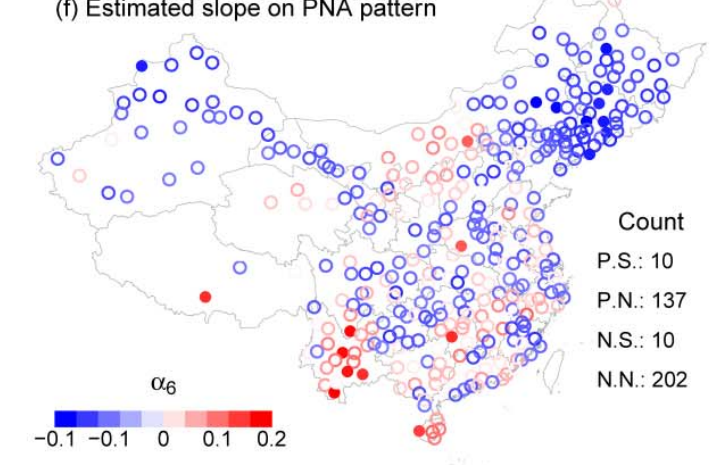

Figure 5. As figure 4 but for $\alpha$ in the Poisson regression model. 

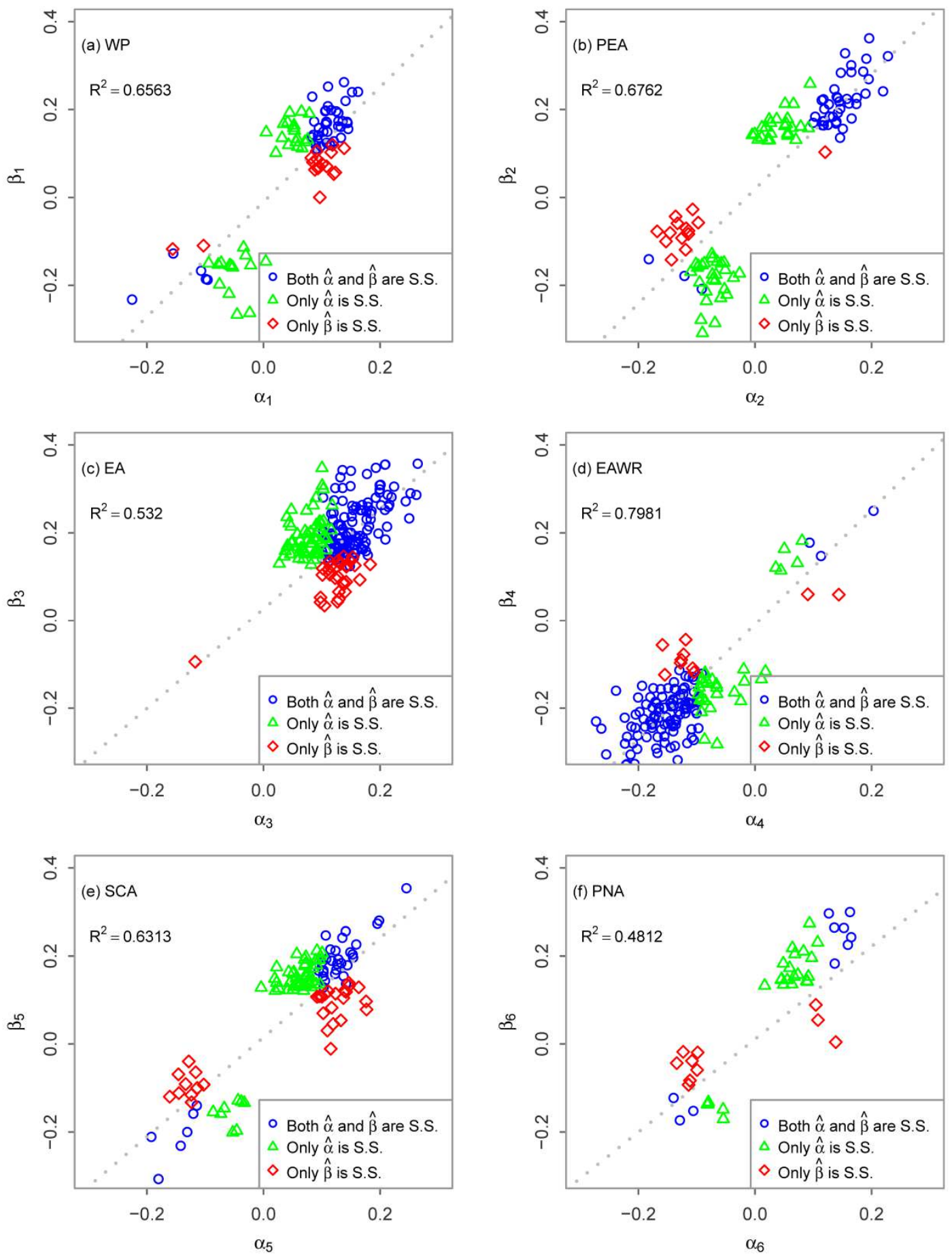

Figure 6. Results of linear regression of $\beta$ in NHPP model with respect to $\alpha$ in the Poisson regression model. S.S. represents statistically significant at the $5 \%$ level. 

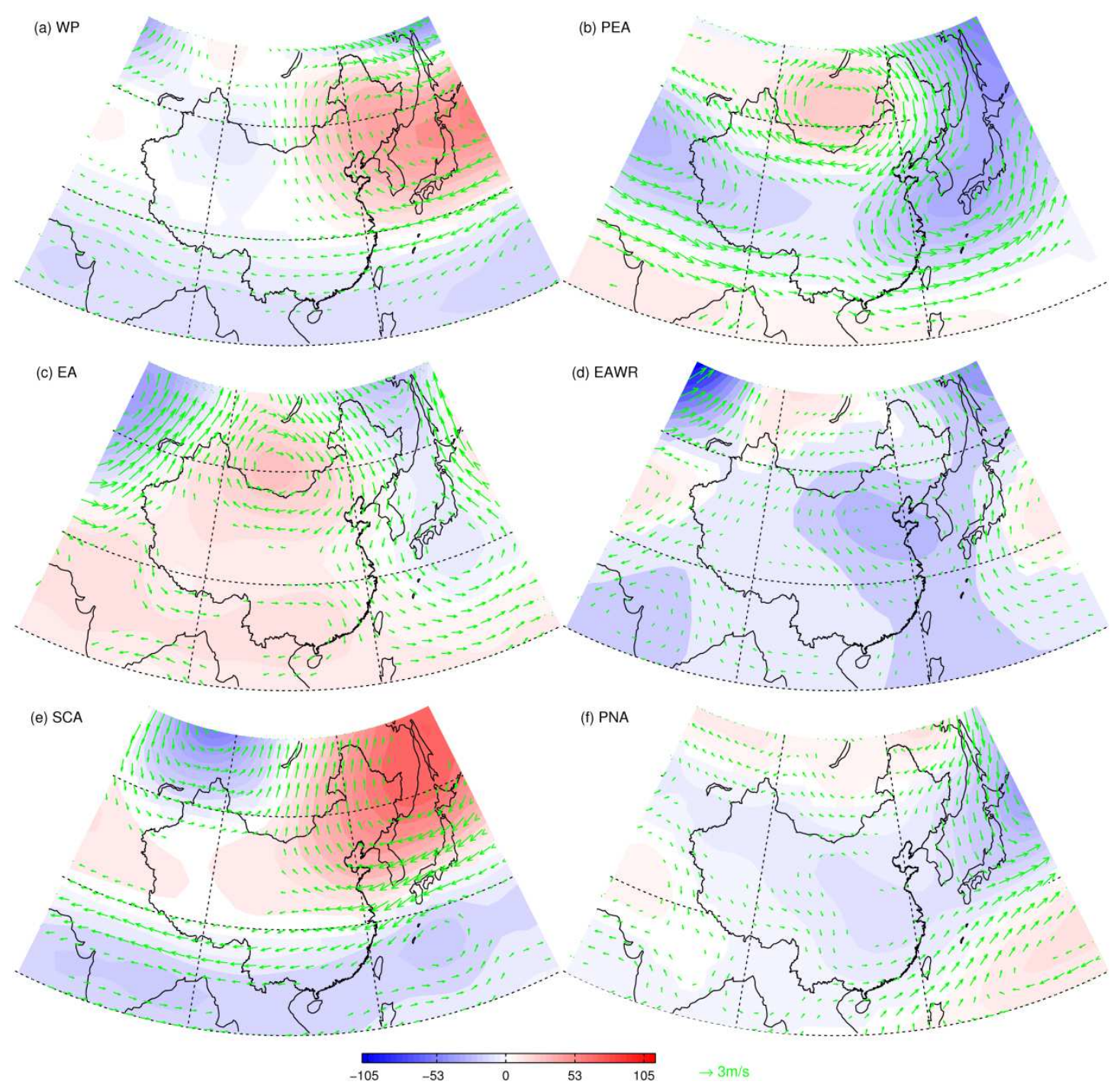

Figure 7. Composite circulation maps of the differences of geopotential height (red and blue shading) and wind fields (green vectors) at 500-hPa pressure level in the positive and negative phases of the six atmospheric teleconnection patterns. The positive/negative phases are denoted as the 20 months in 1956-2013 with highest/lowest teleconnection indices. 